\title{
Barriers to healthy eating among overweight/obese physiotherapy students. Do urban/rural residence or living with/without family have a link?
}

\author{
DOI: https://doi.org/10.5114/pq.2020.96233
}

\author{
Ahmad Mahdi Ahmad', Magda Ramadan Zahran², Heba Mohammed Ali ${ }^{3}$ \\ ${ }^{1}$ Department of Physical Therapy for Cardiovascular and Respiratory Disorders, Faculty of Physical Therapy, Cairo University, \\ Giza, Egypt \\ ${ }^{2}$ Department of Basic Science, Faculty of Physical Therapy, Cairo University, Giza, Egypt \\ ${ }^{3}$ Department of Physical Therapy for Internal Medicine, Faculty of Physical Therapy, Beni Suef University, Beni Suef, Egypt
}

\section{Abstract}

Introduction. The role of students' residence and living status in the perceived barriers to healthy eating warrants attention. This study aimed to assess whether these factors influenced the perceived barriers to healthy eating in physiotherapy students. Methods. A cross-sectional study was conducted in 3 Egyptian universities during the 2018 2nd semester; 404 physiotherapy students aged 18-22 years were recruited. They were overweight and obese, males and females, from all academic levels. The assessment tool was a validated questionnaire comprising 10 items designed to evaluate personal, social, and environmental barriers to healthy eating. A chi-squared test was used for statistical analysis.

Results. In overweight students, there was a significant link between their residence and the perception of the barriers of lack of information, lack of enjoyment, lack of skills, high cost of healthy food, lack of friends' support, lack of faculty staff support $(p<0.05)$. The living status was significantly related with the perception of the barriers of lack of information, lack of skills, lack of access to healthy foods, and high cost of healthy food in overweight students $(p<0.05)$. There was no significant association between the perception of the barrier of lack of time and students' residence or living status.

Conclusions. Residence and/or living status influence the perception of several barriers to healthy eating in overweight physiotherapy students. These observations may aid efforts to promote healthier eating behaviours among overweight/obese students, particularly from rural communities or living away from the family.

Key words: barriers, healthy eating, overweight/obese, physiotherapy students, residence, living status

\section{Introduction}

The prevalence of overweight and obesity has become a growing health problem among college students worldwide [1], and has been found to occur during the $1^{\text {st }}$ college year and continue in the later years of life $[2,3]$. This has been attributed to the unhealthy eating practice in this population, characterized by an increased intake of fast foods and energy drinks rich in fats and calories, as well as a lower intake of low-calorie healthy foods and fruit/vegetables rich in nutrients [4]. In Egypt, unhealthy eating habits and abdominal obesity with resultantly increased prevalence of pre-hypertension and metabolic syndrome are real health problems among university students, particularly female students [58]. A positive correlation existed between excessive weight and/or obesity and higher education levels in Egypt, with a prevalence of obesity and overweight of $68 \%$ and $77 \%$ in males and females with higher education, respectively [9]. Few studies have been conducted to assess the potential barriers to healthy eating among university students in Egypt $[5,6]$. Additional research may be warranted to further investigate this topic from different perspectives. Therefore, this study aimed to determine any associations between the potential barriers to healthy eating perceived by overweight/ obese students and their residence (i.e. urban or rural), or living status (i.e. living with or away from family). The results of this study may shed light on other aspects of perceived barriers to healthy eating, aiding current efforts to better plan an appropriate solution to the unhealthy eating behaviours and the excess body weight among college students.

\section{Subjects and methods}

\section{Research design}

A descriptive cross-sectional study was conducted during the $20182^{\text {nd }}$ semester in 3 faculties of physical therapy in Egypt.

\section{Subjects}

The study recruited 404 physiotherapy college students from 3 universities in Egypt, namely Cairo University, Delta University for Science and Technology, and Beni Suef University. The participants were both males $(n=76)$ and females $(n=328)$, undergraduates from all academic levels, aged 18-22 years. The students were overweight (i.e. body mass index [BMI]: $25-29.9 \mathrm{~kg} / \mathrm{m}^{2}, n=320$ ) or obese (i.e. BMl: $\left.\geq 30 \mathrm{~kg} / \mathrm{m}^{2}, n=84\right)$. The subjects with urban residence were those living in cities and towns, while the individuals with rural residence were those coming from villages. The exclusion criteria were health problems, normal body weight, being married, being a postgraduate student, as well as weight, height, residence, or living status not reported. The demographic and anthropometric characteristics of the physiotherapy students are presented in Table 1.

Correspondence address: Ahmad Mahdi, Faculty of Physical Therapy, Cairo University, 1 Gamaa Street, Giza, Egypt, e-mail: Ahmed.mahdy@pt.cu.edu.eg 
Table 1. Demographic and anthropometric characteristics of the participants

\begin{tabular}{|c|c|c|c|}
\hline \multicolumn{2}{|c|}{ Students' characteristics } & \multirow{2}{*}{$\frac{n}{404}$} & \multirow{2}{*}{$\begin{array}{c}\% \\
100\end{array}$} \\
\hline Age & 18-22 years & & \\
\hline \multirow{2}{*}{ Gender } & Males & 76 & 18.8 \\
\hline & Females & 328 & 81.2 \\
\hline \multirow{2}{*}{ BMI } & Overweight (BMI: $25-29.9$ kg/m²) & 320 & 79.2 \\
\hline & Obese $\left(\mathrm{BMI}: \geq 30 \mathrm{~kg} / \mathrm{m}^{2}\right)$ & 84 & 20.8 \\
\hline \multirow{2}{*}{ Residence } & Urban & 328 & 81.2 \\
\hline & Rural & 76 & 18.8 \\
\hline \multirow{2}{*}{$\begin{array}{l}\text { Living } \\
\text { status }\end{array}$} & Living with family & 280 & 69.3 \\
\hline & Living away from family & 124 & 30.7 \\
\hline
\end{tabular}

\section{Assessment procedures}

\section{Study questionnaire}

An Arabic version of a questionnaire comprising 10 items that represent the potential personal, environmental, and social barriers to healthy eating was used in this study. This Arabic version was previously translated by Musaiger et al. [10] from the original English version [11]. It was tested for validity and reliability among Arabic-speaking college students in Kuwait and showed good validity and reliability [10]. The students were first instructed to report their demographic and anthropometric data on the cover page attached to the questionnaire. These data included university name, academic year, age, residence, living status, body weight, and body height. The participants were then asked to respond to each of the 10 items of the questionnaire in accordance with their own perception; the answer options were: 'very important,' 'somewhat important,' and 'not important'. All personal data were kept anonymous to ensure the confidentiality of the study subjects. Three weeks were allowed to submit the questionnaires.

\section{Calculation of body mass index}

The students reported their body weight and height, and BMI was calculated as body weight $(\mathrm{kg})$ divided by body height $(m)$ squared $\left(m^{2}\right)[12]$.

\section{Data analysis}

\section{Data organization and entry}

For data entry and analysis, we categorized the students into (a) overweight and obese students, depending on their BMI; (b) urban students and rural students, depending on their residence; (c) students living with family and students living away from family, depending on their living status.

\section{Data statistical analysis}

Descriptive statistics were used for data analysis. Percentage frequency distribution served to display the data. A chi-squared test was applied to statistically analyse the associations among the categorical variables in the study. Values of $p<0.05$ were considered statistically significant. The data statistical analysis was performed with the Social Science Statistics software.

\section{Ethical approval}

The research related to human use has complied with all the relevant national regulations and institutional policies, has followed the tenets of the Declaration of Helsinki, and has been approved by the Ethics Committee of Human Scientific Research of the Faculty of Physical Therapy, Cairo University.

\section{Informed consent}

The consent to fill out the questionnaire was considered as the student's written approval to take part in the study.

\section{Results}

Perceived barriers to healthy eating depending on students' residence (i.e. urban or rural)

As shown in Table 2, there was a significant association between the students' residence and their perception of several barriers to healthy eating. Among overweight students, the perception of 6 barriers to healthy eating had a significant link with the residence. These barriers were lack of information about healthy food (i.e. perceived as 'very important' by $21.56 \%$ and $44.44 \%$ of urban and rural students, respectively, $p=0.000$ ), lack of enjoyment during eating healthy food (i.e. perceived as 'very important' by $34.64 \%$ and $28.57 \%$ of urban and rural students, respectively, $p=0.004$ ), lack of skills to prepare healthy foods (i.e. perceived as 'very important' by $20 \%$ and $40.62 \%$ of urban and rural students, respectively, $p=0.002$ ), the high cost of healthy food (i.e. perceived as 'very important' by $9.8 \%$ and $30.15 \%$ of urban and rural students, respectively, $p=0.000$ ), lack of friends' support to eat healthy food (i.e. perceived as 'very important' by $30.46 \%$ and $47.61 \%$ of urban and rural students, respectively, $p=$ $0.024)$, and lack of faculty staff support towards healthy food (i.e. perceived as 'somewhat important' by $26.66 \%$ and $42.85 \%$ of urban and rural students, respectively, $p=0.009$ ). In obese students, the perception of only 2 barriers to healthy eating had a significant association with the residence. These barriers were lack of access to healthy foods (i.e. perceived as 'very important' by $20.28 \%$ and $50 \%$ of urban and rural students, respectively, $p=0.044$ ) and the high cost of healthy foods (i.e. perceived as 'very important' by $11.26 \%$ and $25 \%$ of urban and rural students, respectively, $p=0.019$ ). Worth noting is that there was no significant association between the overweight/obese students' residence and their perception of the barrier of the lack of time $(p>0.05)$, as shown in Table 2.

\section{Perceived barriers to healthy eating depending} on students' living status (i.e. with or without family)

As shown in Table 3, there was a significant association between the students' living status and a number of barriers to healthy eating. Among overweight students, the perception of 4 barriers to healthy eating had a significant link with the living status. These barriers were lack of information about healthy food (i.e. perceived as 'very important' by $18.83 \%$ and $43.29 \%$ of students living with family and those living away from family, respectively, $p=0.000$ ), lack of skills to prepare healthy food (i.e. perceived as 'very important' by $17.41 \%$ and $39.17 \%$ of students living with family and those living away from family, respectively, $p=$ 0.000), lack of access to healthy foods (i.e. perceived as 
Table 2. Perceived barriers to healthy eating among college students by residence

\begin{tabular}{|c|c|c|c|c|c|c|c|c|}
\hline \multirow{2}{*}{ Barriers to healthy eating } & \multirow{2}{*}{ Students } & \multicolumn{3}{|c|}{$\begin{array}{l}\text { Urban students } \\
\text { overweight }(n=256) \text {, } \\
\text { obese }(n=72)\end{array}$} & \multicolumn{3}{|c|}{$\begin{array}{l}\text { Rural students } \\
\text { overweight }(n=64) \text {, } \\
\text { obese }(n=12)\end{array}$} & \multirow{2}{*}{$p$} \\
\hline & & $\begin{array}{c}\text { Very } \\
\text { important } \\
(\%)\end{array}$ & $\begin{array}{c}\text { Somewhat } \\
\text { important } \\
(\%)\end{array}$ & $\begin{array}{l}\text { Not } \\
\text { important } \\
(\%)\end{array}$ & $\begin{array}{l}\text { Very } \\
\text { important } \\
\text { (\%) }\end{array}$ & $\begin{array}{c}\text { Somewhat } \\
\text { important } \\
(\%)\end{array}$ & $\begin{array}{l}\text { Not } \\
\text { important } \\
(\%)\end{array}$ & \\
\hline \multicolumn{9}{|l|}{ Personal and environmental barriers } \\
\hline \multirow{2}{*}{$\begin{array}{l}\text { 1. Do not have enough information } \\
\text { about a healthy diet }\end{array}$} & Overweight & 21.56 & 43.52 & 34.90 & 44.44 & 38.09 & 17.46 & $0.000^{*}$ \\
\hline & Obese & 12.67 & 46.47 & 40.84 & 25 & 50 & 25 & 0.411 \\
\hline \multirow{2}{*}{$\begin{array}{l}\text { 2. Do not have the motivation to eat } \\
\text { a healthy diet }\end{array}$} & Overweight & 30.58 & 47.05 & 22.35 & 31.74 & 42.85 & 25.39 & 0.811 \\
\hline & Obese & 35.71 & 42.85 & 21.42 & 25 & 33.33 & 41.66 & 0.318 \\
\hline \multirow{2}{*}{ 3. Do not enjoy eating healthy foods } & Overweight & 34.64 & 47.63 & 17.71 & 28.57 & 34.92 & 36.50 & $0.004^{*}$ \\
\hline & Obese & 39.43 & 39.43 & 21.12 & 33.33 & 58.33 & 8.33 & 0.398 \\
\hline \multirow{2}{*}{$\begin{array}{l}\text { 4. Do not have skills to plan, shop for, } \\
\text { prepare, or cook healthy foods }\end{array}$} & Overweight & 20 & 48.23 & 31.76 & 40.62 & 32.81 & 26.56 & $0.002^{*}$ \\
\hline & Obese & 29.57 & 33.80 & 36.61 & 33.33 & 41.66 & 25 & 0.731 \\
\hline \multirow{2}{*}{ 5. Do not have access to healthy foods } & Overweight & 18.25 & 32.93 & 48.80 & 29.68 & 26.56 & 43.75 & 0.124 \\
\hline & Obese & 20.28 & 18.84 & 60.86 & 50 & 25 & 25 & $0.044^{*}$ \\
\hline \multirow{2}{*}{$\begin{array}{l}\text { 6. Not able to buy expensive } \\
\text { healthy foods }\end{array}$} & Overweight & 9.80 & 28.23 & 61.96 & 30.15 & 41.26 & 28.57 & $0.000^{*}$ \\
\hline & Obese & 11.26 & 21.12 & 67.60 & 25 & 50 & 25 & $0.019^{*}$ \\
\hline \multicolumn{9}{|l|}{ Social barriers } \\
\hline \multirow{2}{*}{$\begin{array}{l}\text { 1. No parents' support to eat } \\
\text { a healthy diet }\end{array}$} & Overweight & 22.35 & 29.01 & 48.62 & 26.56 & 23.43 & 50 & 0.612 \\
\hline & Obese & 9.85 & 26.76 & 63.38 & 25 & 25 & 50 & 0.322 \\
\hline \multirow{2}{*}{$\begin{array}{l}\text { 2. No friends' support to eat } \\
\text { a healthy diet }\end{array}$} & Overweight & 30.46 & 42.18 & 27.34 & 47.61 & 26.98 & 25.39 & $0.024^{*}$ \\
\hline & Obese & 26.76 & 40.84 & 32.39 & 50 & 25 & 25 & 0.260 \\
\hline \multirow{2}{*}{$\begin{array}{l}\text { 3. No faculty staffs support to eat } \\
\text { a healthy diet }\end{array}$} & Overweight & 17.64 & 26.66 & 55.68 & 22.22 & 42.85 & 34.92 & $0.009^{*}$ \\
\hline & Obese & 7.04 & 28.16 & 64.78 & 25 & 41.66 & 33.33 & 0.056 \\
\hline \multirow{2}{*}{$\begin{array}{l}\text { 4. Not having time to prepare or eat } \\
\text { healthy foods because of university } \\
\text { commitment }\end{array}$} & Overweight & 55.29 & 30.58 & 14.11 & 57.81 & 21.87 & 20.31 & 0.261 \\
\hline & Obese & 52.77 & 34.72 & 12.5 & 50 & 25 & 25 & 0.488 \\
\hline
\end{tabular}

Data are presented as percentage frequency distribution.

* significant $p$ values (i.e. $<0.05)$ from chi-squared test

'very important' by $15.38 \%$ and $32.98 \%$ of students living with family and those living away from family, respectively, $p=0.000$ ), and the high cost of healthy foods (i.e. perceived as 'very important' by $7.62 \%$ and $27.83 \%$ of students living with family and those living away from family, respectively, $p=0.000$ ). In obese students, the perception of only 1 barrier to healthy eating had a significant association with the living status. This barrier was the high cost of healthy food (i.e. perceived as 'very important' by $7.27 \%$ and $25.92 \%$ of students living with family and those living away from family, respectively, $p=0.015)$. Notably, there was no significant association between the overweight/ obese students' living status and their perception of the barrier of the lack of time $(p>0.05)$, as shown in Table 3 .

\section{Discussion}

College life is a new life for students, especially those coming from rural backgrounds or moving out for college far away from their families. The purpose of this study was ral) or the living status (i.e. living with or away from family) of physiotherapy college students and their perception of the personal, environmental, and social barriers to healthy eating. The major findings were the following: (a) The residence had a significant association with the subjective perception of several barriers to healthy eating in overweight students. (b) The living status also presented a significant association with the perception of a number of barriers to healthy eating in overweight students. (c) The lack of time to prepare healthy food was perceived by most overweight and obese students as a 'very important' barrier to healthy eating, regardless of their residence or living status. (d) The lack of parents' support to eat a healthy diet was perceived as a 'not important' barrier to healthy eating by most overweight and obese students, regardless of their residence or living status.

With reference to the residence, our study showed that it was significantly linked with the subjective perception of 6 barriers to healthy eating among overweight college students. These barriers were lack of information, lack of enjoyment, lack of skills, high price of healthy foods, lack of 
Table 3. Perceived barriers to healthy eating among college students by living status

\begin{tabular}{|c|c|c|c|c|c|c|c|c|}
\hline \multirow{2}{*}{ Barriers to healthy eating } & \multirow{2}{*}{ Students } & \multicolumn{3}{|c|}{$\begin{array}{l}\text { Students living with family } \\
\text { overweight }(n=224) \\
\text { obese }(n=56)\end{array}$} & \multicolumn{3}{|c|}{$\begin{array}{c}\text { Students living away from family } \\
\text { overweight }(n=97) \\
\text { obese }(n=27)\end{array}$} & \multirow{2}{*}{$p$} \\
\hline & & $\begin{array}{c}\text { Very } \\
\text { important } \\
(\%)\end{array}$ & $\begin{array}{c}\text { Somewhat } \\
\text { important } \\
(\%)\end{array}$ & $\begin{array}{c}\text { Not } \\
\text { important } \\
(\%)\end{array}$ & $\begin{array}{c}\text { Very } \\
\text { important } \\
(\%)\end{array}$ & $\begin{array}{c}\text { Somewhat } \\
\text { important } \\
(\%)\end{array}$ & $\begin{array}{c}\text { Not } \\
\text { important } \\
(\%)\end{array}$ & \\
\hline
\end{tabular}

Personal and environmental barriers

\begin{tabular}{|c|c|c|c|c|c|c|c|c|}
\hline \multirow{2}{*}{$\begin{array}{l}\text { 1. Do not have enough information } \\
\text { about a healthy diet }\end{array}$} & Overweight & 18.83 & 45.73 & 35.42 & 43.29 & 36.08 & 20.61 & $0.000^{*}$ \\
\hline & Obese & 16.07 & 42.85 & 41.07 & 7.69 & 57.69 & 34.61 & 0.378 \\
\hline \multirow{2}{*}{$\begin{array}{l}\text { 2. Do not have the motivation to eat } \\
\text { a healthy diet }\end{array}$} & Overweight & 30.94 & 47.98 & 21.07 & 28.86 & 44.32 & 26.80 & 0.532 \\
\hline & Obese & 34.54 & 45.45 & 20 & 30.76 & 34.61 & 34.61 & 0.350 \\
\hline \multirow{2}{*}{ 3. Do not enjoy eating healthy foods } & Overweight & 35.13 & 46.39 & 18.46 & 28.86 & 42.26 & 28.86 & 0.109 \\
\hline & Obese & 39.28 & 44.64 & 16.07 & 34.61 & 38.46 & 26.92 & 0.513 \\
\hline \multirow{2}{*}{$\begin{array}{l}\text { 4. Do not have skills to plan, shop for, } \\
\text { prepare, or cook healthy foods }\end{array}$} & Overweight & 17.41 & 48.21 & 34.37 & 39.17 & 39.17 & 21.64 & $0.000^{*}$ \\
\hline & Obese & 28.57 & 33.92 & 37.5 & 30.76 & 38.46 & 30.76 & 0.835 \\
\hline \multirow{2}{*}{ 5. Do not have access to healthy foods } & Overweight & 15.38 & 30.31 & 54.29 & 32.98 & 35.05 & 31.95 & $0.000^{*}$ \\
\hline & Obese & 20 & 18.18 & 61.81 & 36 & 24 & 40 & 0.170 \\
\hline \multirow{2}{*}{$\begin{array}{l}\text { 6. Not able to buy expensive } \\
\text { healthy foods }\end{array}$} & Overweight & 7.62 & 28.69 & 63.67 & 27.83 & 35.05 & 37.11 & $0.000^{*}$ \\
\hline & Obese & 7.27 & 21.81 & 70.90 & 25.92 & 33.33 & 40.74 & $0.015^{\star}$ \\
\hline \multicolumn{9}{|l|}{ Social barriers } \\
\hline \multirow{2}{*}{$\begin{array}{l}\text { 1. No parents' support to eat } \\
\text { a healthy diet }\end{array}$} & Overweight & 22.32 & 27.67 & 50 & 26.80 & 27.83 & 45.36 & 0.645 \\
\hline & Obese & 10.71 & 28.57 & 60.71 & 11.53 & 23.07 & 65.38 & 0.872 \\
\hline \multirow{2}{*}{$\begin{array}{l}\text { 2. No friends' support to eat } \\
\text { a healthy diet }\end{array}$} & Overweight & 31.25 & 40.17 & 28.57 & 39.17 & 36.08 & 24.74 & 0.383 \\
\hline & Obese & 28.57 & 39.28 & 32.14 & 30.76 & 38.46 & 30.76 & 0.978 \\
\hline \multirow{2}{*}{$\begin{array}{l}\text { 3. No faculty staff support to eat } \\
\text { a healthy diet }\end{array}$} & Overweight & 17.04 & 27.35 & 55.60 & 21.64 & 36.08 & 42.26 & 0.089 \\
\hline & Obese & 7.14 & 30.35 & 62.5 & 11.53 & 30.76 & 57.69 & 0.790 \\
\hline \multirow{2}{*}{$\begin{array}{l}\text { 4. Not having time to prepare or eat } \\
\text { healthy foods because of university } \\
\text { commitment }\end{array}$} & Overweight & 53.12 & 32.14 & 14.73 & 62.88 & 21.64 & 15.46 & 0.153 \\
\hline & Obese & 48.21 & 35.71 & 16.07 & 59.25 & 29.62 & 11.11 & 0.625 \\
\hline
\end{tabular}

Data are presented as percentage frequency distribution.

${ }^{*}$ significant $p$ values (i.e. $<0.05$ ) from chi-squared test

friends' support, and lack of faculty staff support to eat a healthy diet. Among obese participants, 2 perceived barriers to healthy eating had a significant link with residence, namely lack of access to healthy foods and the high cost of healthy food. The role of residence in the perceived barriers to healthy eating may be supported by an earlier study [13], where the authors found that residence or where students lived affected their eating habits and food selection. In our study, the barrier of lack of information turned out 'very important' for $21.56 \%$ of urban overweight students vs. $44.44 \%$ of rural overweight students. This shows that students coming from rural areas have a relatively poor understanding of the healthy diet. This observation can be supported by Whelan et al. [14], who revealed that nutrition information and nutrition promotion were not available in the rural community. Also, the lack of enjoyment was perceived as a 'very important' barrier by $34.64 \%$ of urban overweight students vs. $28.57 \%$ of rural overweight students in the present study. It has been found that the preference for the taste of unhealthy foods and snacks is an important barrier to healthy eating in both urban and rural communities [15]. The college students' choice of food seems to be dependent on taste preference and convenience rather than on the nutritional value [16]. Furthermore, our study indicated that the high cost of healthy food was perceived as a 'very important' barrier by $9.8 \%$ of urban overweight students vs. $30.15 \%$ of rural overweight students. This barrier was also perceived as 'very important' by $11.26 \%$ of urban obese students vs. $25 \%$ of rural obese students. This observation was also reported by Seguin et al. [17], who implied that the high costs of healthy foods represented the main barrier to healthy eating practice in the rural community. For rural communities, it is harder to afford nutritious food than in urban communities [18]. Moreover, our study showed that lack of friends' support to eat healthy food was perceived as a 'very important' barrier by $30.46 \%$ of urban overweight students and by $47.61 \%$ of rural overweight students. College students most commonly form groups who are used to eating out together in fast food cafeterias or restaurants; thus, the choice to eat either healthy or unhealthy food can be made under the influence of friends' choices. According to the social cognitive theory, college students can be easily influenced by the dietary behaviours of their peers. 
By adopting the eating behaviours of their friends, college students can have a sense of inclusion, self-confidence, and acceptance [19]. Notably, the present study showed that the barrier of lack of access to healthy foods was significantly related with residence only in obese students and was perceived as a 'very important' barrier by $20.28 \%$ of urban students vs. $50 \%$ of rural students. It has been found that rural communities have poor access to healthy food stores compared with urban areas $[14,18]$. The lack of access to healthy foods is more common in rural areas because of the geographical isolation of these regions [20].

As for the living status, our study revealed that it was significantly linked with the subjective perception of 4 barriers to healthy eating among overweight college students. These barriers were lack of information, lack of skills, lack of access to healthy foods, and higher price for healthy food. Lack of information was perceived as a 'very important' barrier by $18.83 \%$ of overweight students living with family vs. $43.29 \%$ of overweight students living away from family. Lack of skills was perceived as a 'very important' barrier by $17.41 \%$ of overweight students living with family vs. $39.17 \%$ of overweight students living away from family. Furthermore, lack of access to healthy foods was perceived as a 'very important' barrier by $15.38 \%$ of overweight students living with family vs. $32.98 \%$ of overweight students living away from family. Moreover, our study implied that the higher price for healthy food was perceived as a 'very important' barrier by $7.62 \%$ and $7.27 \%$ of overweight and obese students living with their families, respectively, vs. $27.83 \%$ and $25.92 \%$ of overweight and obese students living away from family, respectively. On this basis, it is obvious that the students who lived away from family were more restricted by the aforementioned barriers than the individuals living at home with their families. College students who live with their families adopt healthier eating practices, characterized by a more frequent intake of fruit, vegetables, fish, meat, eggs, grains/breads, and legumes, which is not the case for students living away from family, who show an increased intake of fast foods, sweets, carbonated beverages, and calorie-dense food [21]. Besides, cooking and eating at home are associated with healthier food choices while eating away from home implies increased consumption of unhealthy foods [22-24].

Of interest, this study has shown that lack of time to prepare or cook healthy food was a 'very important' barrier for large numbers of overweight and obese students, regardless of their residence or living status. Several studies support this finding [25-27]. Conversely, lack of parents' support was perceived as a 'not important' barrier by numerous overweight and obese students, regardless of their residence or living status. Indeed, the support of parents in developing healthy eating practices is not perceived as an important factor by college students [10].

Worth noting is that the non-adherence to overall healthy food recommendations is not solely dependent on one barrier to healthy foods, but rather on a combination of multiple barriers. For example, regarding the lack of information about a healthy diet, college students may understand the unhealthiness of fast food and still continue to eat it because it is tasty; thus, many factors other than knowledge could come in [28]. Besides, despite the accessibility of supermarkets selling highquality food, college students may choose to buy a diet of lower quality because it is cheaper, which reflects the interdependence of these barriers [29]. Furthermore, regarding lack of time owing to studying commitments, college students may prefer to spend their free time in a different way than preparing or cooking healthy foods; and if they have to cook, they may want to cook quickly prepared unhealthy foods and spend more time watching television [25].

\section{Limitations and recommendations}

The limitations of this study include the disproportion between male and female students in the sample; this resulted from the fact that the majority of physiotherapy students at the 3 universities were females. Lack of recruitment of college students other than physiotherapy students represents another limitation. Furthermore, there is an inability to deduce a cause-and-effect relationship because of the cross-sectional nature of the study; however, observing the associations between the categorical variables of interest could still be useful. Recommendations of this study include paying more attention to the eating practice of the overweight/obese college students who come from rural communities or live away from home. Another recommendation is to overcome personal, social, and environmental barriers to healthy eating as perceived by overweight/obese college students by: (a) nutrition educational courses or symposiums concerning healthy diet benefits and choices organized by universities; (b) development of skills needed to easily prepare healthy foods, making healthy diet planning less time-consuming, and nutritional education using smartphone applications, as previously considered as an appealing tool for health promotion among new generations of college students [30]; (c) verifying the university policy with regard to the pricing of healthy foods; less expensive healthy food should be available to help develop healthy eating practices, especially among rural or other low-income students. All the above could make the university a health-promoting environment that emphasizes healthful eating behaviours among students, especially overweight/obese students who come from rural areas or live away from home.

\section{Conclusions}

Both the residence (i.e. urban or rural) and the living status (i.e. with or without family) of overweight physiotherapy college students have a link with their subjective perception of a number of barriers to healthy eating, including the lack of information about a healthy diet, the lack of skills to prepare healthy food, and the inability to buy expensive healthy foods. The lack of time to prepare healthy food was perceived as a 'very important' barrier and the lack of parents' support to eat a healthy diet was perceived as a 'not important' barrier by higher percentages of overweight/obese physiotherapy students, regardless of their residence or living status. The knowledge of the perceived barriers to healthy eating among overweight/obese physiotherapy students, as a sample of college students, and understanding the associations between these barriers and the students' residence or living status can be the key to newly designed nutritional strategies and policies that would promote healthier eating practices in the environment of the university.

\section{Disclosure statement}

No author has any financial interest or received any financial benefit from this research.

\section{Conflict of interest}

The authors state no conflict of interest. 


\section{References}

1. Meng JS, Yang FZ, Peng G, Weng JX. Systematic estimation of BMI. A novel insight into predicting overweight/ obesityinundergraduates.Medicine.2019;98(21):e15810; doi: 10.1097/MD.0000000000015810.

2. Anderson DA, Shapiro JR, Lundgren JD. The freshman year of college as a critical period for weight gain: an initial evaluation. Eat Behav. 2003;4(4):363-367; doi: 10.1016/ S1471-0153(03)00030-8.

3. Racette SB, Deusinger SS, Strube MJ, Highstein GR, Deusinger $\mathrm{RH}$. Weight changes, exercise, and dietary patterns during freshman and sophomore years of college. J Am Coll Health. 2005;53(6):245-251; doi: 10.3200/ JACH.53.6.245-251.

4. Bernardo GL, Jomori MM, Fernandes AC, Proenca RPC. Food intake of university students. Rev Nutr. 2017;30(6): 847-865; doi: 10.1590/1678-98652017000600016.

5. Genena DM, Salama AA. Obesity and eating habits among university students in Alexandria, Egypt: a cross sectional study. World J Nutr Health. 2017;5(3):62-68; doi: 10.12691/jnh-5-3-1.

6. El-Bagoury L, Hassan A, AbouSeif $\mathrm{H}$. Eating attitudes and barriers to healthy eating and physical activity among a sample of university students in Egypt. J Egypt Public Health Assoc. 2017;92(1):29-35; doi: 10.21608/epx.2017. 7007.

7. Farrag A, Eraky AE, Aroussy WE, Sayed G, Mahrous A, Adel A, et al. Obesity and other cardiovascular risk factors in Egyptian university students: magnitude of the problem. Epidemiology. 2015;5(1):181; doi: 10.4172/21611165.1000181.

8. Ahmed MM, Ellithy MA, Hamed AM, Kasem SH. Prevalence of metabolic syndrome among obese Egyptian college students. Med J Cairo Univ. 2014;82(2):305-311.

9. Taylor C. Higher education, student health, and obesity in developing countries. Int High Educ. 2017;90:13-15; doi: 10.6017/ihe.2017.90.9998.

10. Musaiger AO, Al-Kandari FI, Al-Mannai M, Al-Faraj AM, Bouriki FA, Shehab FS, et al. Perceived barriers to weight maintenance among university students in Kuwait: the role of gender and obesity. Environ Health Prev Med. 2014;19(3):207-214; doi: 10.1007/s12199-013-0377.

11. Andajani-Sutjahjo S, Ball K, Warren N, Inglis V, Crawford D. Perceived personal, social and environmental barriers to weight maintenance among young women: a community survey. Int J Behav Nutr Phys. 2004;1(1): 15; doi: 10.1186/1479-5868-1-15.

12. American Diabetes Association. 7. Obesity management for the treatment of type 2 diabetes: standards of medical care in diabetes - 2018. Diabetes Care. 2018;41(Suppl. 1):S65-S72; doi: 10.2337/dc18-S007.

13. Brevard PB, Ricketts CD. Residence of college students affects dietary intake, physical activity, and serum lipid levels. J Am Diet Assoc. 1996;96(1):35-38; doi: 10.1016/ S0002-8223(96)00011-9.

14. Whelan J, Millar L, Bell C, Russell C, Grainger F, Allender S, et al. You can't find healthy food in the bush: poor accessibility, availability and adequacy of food in rural Australia. Int J Environ Res Public Health. 2018;15(10): 2316; doi: 10.3390/ijerph15102316.

15. Jilcott SB, Laraia BA, Evenson KR, Ammerman AS. Perceptions of the community food environment and related influences on food choice among midlife women residing in rural and urban areas: a qualitative analysis. Women Health. 2009;49(2-3):164-180; doi: 10.1080/03 630240902915085.
16. Abraham S, Brooke RN, Shin JY. College students eating habits and knowledge of nutritional requirements. J Nutr Hum Health. 2018;2(1):13-17.

17. Seguin R, Connor L, Nelson M, LaCroix A, Eldridge G. Understanding barriers and facilitators to healthy eating and active living in rural communities. J Nutr Metab. 2014;2014:146502; doi: 10.1155/2014/146502.

18. Gittelsohn J, Rowan M, Gadhoke P. Interventions in small food stores to change the food environment, improve diet, and reduce risk of chronic disease. Prev Chronic Dis. 2012;9:E59; doi: 10.5888/pcd9.110015.

19. Burchell K, Rettie R, Patel K. Marketing social norms: social marketing and the 'social norm approach'. J Consum Behav. 2013;12(1):1-9; doi: 10.1002/cb.1395C.

20. Hardin-Fanning F, Rayens MK. Food cost disparities in rural communities. Health Promot Pract. 2015;16(3): 383-391; doi: 10.1177/1524839914554454.

21. Papadaki A, Hondros G, Scotta JA, Kapsokefalou M. Eating habits of university students living at, or away from home in Greece. Appetite. 2007;49(1):169-176; doi: 10.1016/j.appet.2007.01.008.

22. McLaughlin C, Tarasuk V, Kreiger N. An examination of at-home food preparation activity among low-income, food-insecure women. J Am Diet Assoc. 2003;103(11): 1506-1512; doi: 10.1016/j.jada.2003.08.022.

23. Van der Horst K, Brunner TA, Siegrist M. Ready-meal consumption: associations with weight status and cooking skills. Public Health Nutr. 2011;14(2):239-245; doi: $10.1017 /$ S1368980010002624.

24. Garcia AL, Reardon R, McDonald M, Vargas-Garcia EJ. Community interventions to improve cooking skills and their effects on confidence and eating behaviour. Curr Nutr Rep. 2016;5(4):315-322; doi: 10.1007/s13668016-0185-3.

25. Deliens T, Clarys P, De Bourdeaudhuij I, Deforche B. Determinants of eating behaviour in university students: a qualitative study using focus group discussions. BMC Public Health. 2014;14:53; doi: 10.1186/1471-2458-14-53.

26. Oh Y, Kang BJ, Yoo S, Lopez A. Overweight and obese college students' perceived barriers and motivators for a healthy lifestyle. Eur J Educ Sci. 2016;3(4):17-26; doi: 10.19044/ejes.v3no4a17.

27. Ashton LM, Hutchesson JM, Rollo ME, Morgan PJ, Collins CE. Motivators and barriers to engaging in healthy eating and physical activity: a cross-sectional survey in young adult men. Am J Mens Health. 2017;11(2):330343; doi: 10.1177/1557988316680936.

28. Stockton S, Baker D. College students' perceptions of fast food restaurant menu items on health. Am J Health Educ. 2013;44(2):74-80; doi: 10.1080/19325037.2013.764242.

29. Rummo PE, Meyer KA, Boone-Heinonen J, Jacobs Jr DR, Kiefe $\mathrm{Cl}$, Lewis CE, et al. Neighbourhood availability of convenience stores and diet quality: findings from 20 years of follow-up in the coronary artery risk development in young adults study. Am J Public Health. 2015;105(5):6573; doi: 10.2105/AJPH.2014.302435.

30. Miller T, Chandler L, Mouttapa M. A needs assessment, development, and formative evaluation of a health promotion smartphone application for college students. Am J Health Educ. 2015;46(4):207-215; doi: 10.1080/1932 5037.2015.1044138. 